\title{
Joinpoint Regression Analysis of Potential Years of Life Lost Due to Main Causes of Death in Poland, Years 2002-2011
}

\author{
Michalina Krzyżak ${ }^{1}$, Dominik Maślach ${ }^{1}$, Martyna Skrodzka², \\ Katarzyna Florczyk ${ }^{2}$, Anna Szpak ${ }^{3}$, Bartosz Pędziński ${ }^{1}$, \\ Paweł Sowa ${ }^{1}$, Andrzej Szpak ${ }^{1}$ \\ 1 Department of Public Health, Medical University of Bialystok, Poland \\ 2 Students Scientific Group of Public Health, Department of Public Health, Medical Uni- \\ versity of Bialystok, Poland \\ 3 Department of Restorative Dentistry, Medical University of Bialystok, Poland
}

\begin{abstract}
The purpose of the study was to analyse the level and the trends of Potential Years of Life Lost due to the main causes of death in Poland in the years 2002-2011. The material for the study was the information from the Central Statistical Office on the number of deaths due to the main causes of death in Poland in the years 2002-2011. The premature mortality analysis was conducted with the use of the PYLL (Potential Years of Life Lost) indicator. PYLL rate was calculated following the method proposed by J. Romeder, according to which premature mortality was defined as death before the age of 70 . Time trends of PYLL rate and the average annual percent change (APC - Annual Percent Change) were assessed using jointpoint models and the Joinpoint Regression Program. In the years 2002-2011, PYLL rate for all-cause deaths decreased by $7.0 \%$ among men and $8.1 \%$ among women. In 2011, the main reasons for PYLL among men were: external causes $(27.6 \%)$, cardiovascular diseases $(24.2 \%)$ and cancers $(20.3 \%)$. Among women the leading causes were: cancers $(41.1 \%)$, cardiovascular diseases $(19.7 \%)$ and external causes $(12.5 \%)$. PYLL rate increased among men for colorectal cancer, and among women for colorectal and lung cancer. The presented epidemiological situation for premature mortality in Poland shows that in the majority of cases it is caused by preventable deaths, which highlights a need to intensify measures in primary and secondary prevention.
\end{abstract}

\section{Introduction}

Premature deaths in younger age groups influence societies in their social and economic aspects; therefore, reduction of the number of these deaths is an important aim for activities undertaken within the public health sector.

A traditional premature mortality indicator shows the rate of deaths in a population and allows for the analysis of time trends and the comparison 


\section{Michalina Krzyżak et al.}

of premature mortality in various populations but it does not include social and economic burdens imposed on a society by premature deaths. Therefore, the Potential Years of Life Lost (PYLL) rate has been introduced, which is an addition to the premature mortality analysis, as it includes the number of deaths resulting from a particular cause as well as the age at death (Gardner et al., 1990; Romeder et al., 1977).

PYLL rate is an indicator that arbitrarily assumes a limit of life expectancy, e.g. in OECD countries, it is set at the age of 70 (OECD, 2011). A death at the age of 30 is accountable for 40 potential years of life lost. Therefore, deaths in younger age groups cause greater social and economic burdens of loss because they are the reasons for more potential years of life lost. In Poland, the use of a synthetic PYLL rate in epidemiological studies is not widespread.

The purpose of the study was to analyse the level and the trends of Potential Years of Life Lost due to the main causes of death in Poland in the years 2002-2011.

\section{Material and Methods}

The material was based on the data from the Central Statistical Office of Poland on the number of deaths registered in the years 2002-2011. Causes of death were coded according to the $10^{\text {th }}$ revision of the International Classification of Diseases (World Health Organization, 2004).

PYLL were calculated according to the method proposed by Romeder (1977). The number of deaths in 5-year age groups was used to calculate the PYLL in Poland in years 2002-2011. The calculations were made according to the formula:

where

$$
\mathrm{PYLL}=\sum_{i=1}^{70} d_{i} \cdot(70-i)
$$

- 70 is the cut-off age before the occurrence of death

- $i$ is the average number of potential years of life lost due to causes of death registered for the given age group (e.g. 42.5 years for the age group 25-29)

- $d_{i}$ is the number of deaths in $i$ age group.

The PYLL rate was calculated as a quotient of the PYLL number and the number of inhabitants in Poland in the age group 1-69. The PYLL rate was calculated per 100000 people, separately for both sexes. 
Time trends for the PYLL rate in the years 2002-2011 in Poland were analysed for general-causes of death and three main categories of death: cancer, cardiovascular diseases, and external causes. Moreover, some causes of more relevant impact on premature mortality were selected from the main causes of death. The categories of causes of death used in the analysis are shown in Table 1.

Table 1. Cause of death categories used in the analysis

\begin{tabular}{|l|c|}
\hline Cause of death categories & $\begin{array}{c}\text { Classification of diseases } \\
\text { according to ICD 10 }\end{array}$ \\
\hline All causes & A02.0 - Y89.9 \\
\hline Cancer & C00 - C97 \\
Colorectal cancer & C18 - C21 \\
Lung cancer & C33- C34 \\
Breast cancer & C50 \\
Cervical cancer & C53 \\
\hline Cardiovascular diseases & I00 - I99 \\
Ischemic heart diseases & I20 - I25 \\
Cerebrovascular diseases & I60 - I69 \\
\hline External causes & V01 - Y89 \\
Traffic accidents & V01-V99 \\
Suicides & X60 - X84 \\
\hline
\end{tabular}

The changes in PYLL rates for each cause were analysed using the joinpoint software, using a log-linear model assuming constant variance. This method is an extension of the linear regression model, in which the time trend is determined by the joined segments (joinpoints) in which changes in time trends occur in a statistically significant way by performing several permutation tests (Kim et al., 2000).

On the basis of the linear regression model, in which the natural logarithm of the PYLL rate was a dependent variable and the calendar year was an independent variable $(y=a+b x$, where $y=\ln$ (PYLL rate), $x=$ calendar year), Annual Percent Change (APC) of PYLL rates for each trend was determined according to the following formula:

$$
\mathrm{APC}=100 \cdot\left(\exp ^{b}-1\right) .
$$

A 95\% confidence interval was set in order to estimate the statistical significance of the APC level in the analysed period. The trends and APC were analysed using the Joinpoint Regression Program, Version 4.0.4 (National Cancer Institute, Statistical Research and Applications Branch, 2013). 


\section{Michalina Krzyżak et al.}

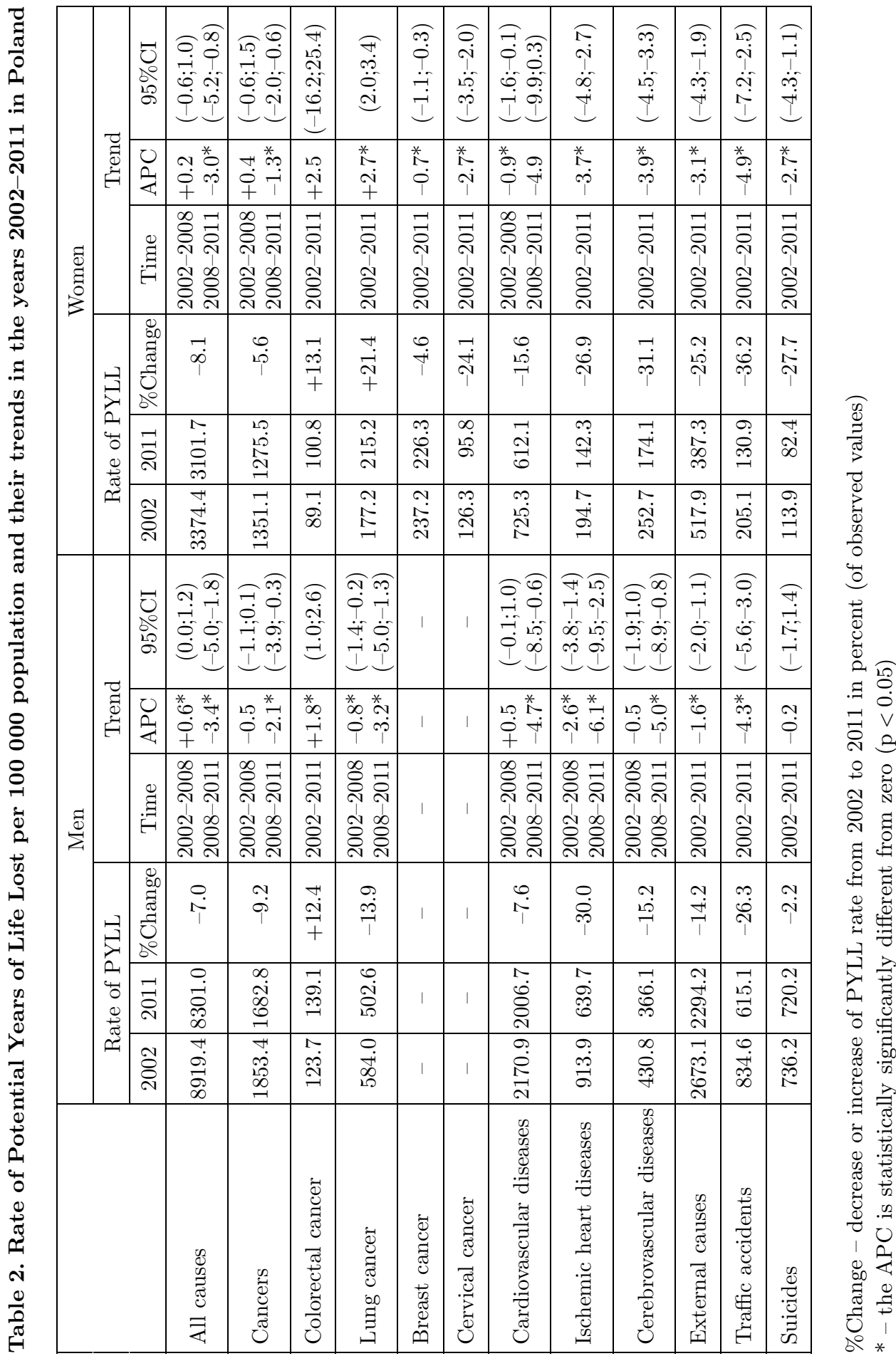


Joinpoint Regression Analysis of Potential Years of Life Lost Due to Main...

\section{Results}

As presented in Table 2, in the years 2002-2008, PYLL rate for men for all causes of death increased by $0.6 \%$ per year $(p<0.05)$. After 2008 , the trend changed and decreased, and the PYLL rate continued to decrease by $3.4 \%$ per year $(p<0.05)$ until 2011. Among women the trend also increased by $0.2 \%$ per year until 2008 and then continued to decrease by $3.0 \%$ per year $(p<0.05)$, as presented in Figure 1. The PYLL rate for all causes of death was almost three times higher among men than women. Among men in 2011, PYLL amounted to $8301.0 / 10^{5}$; among women, it amounted to $3101.7 / 10^{5}$.

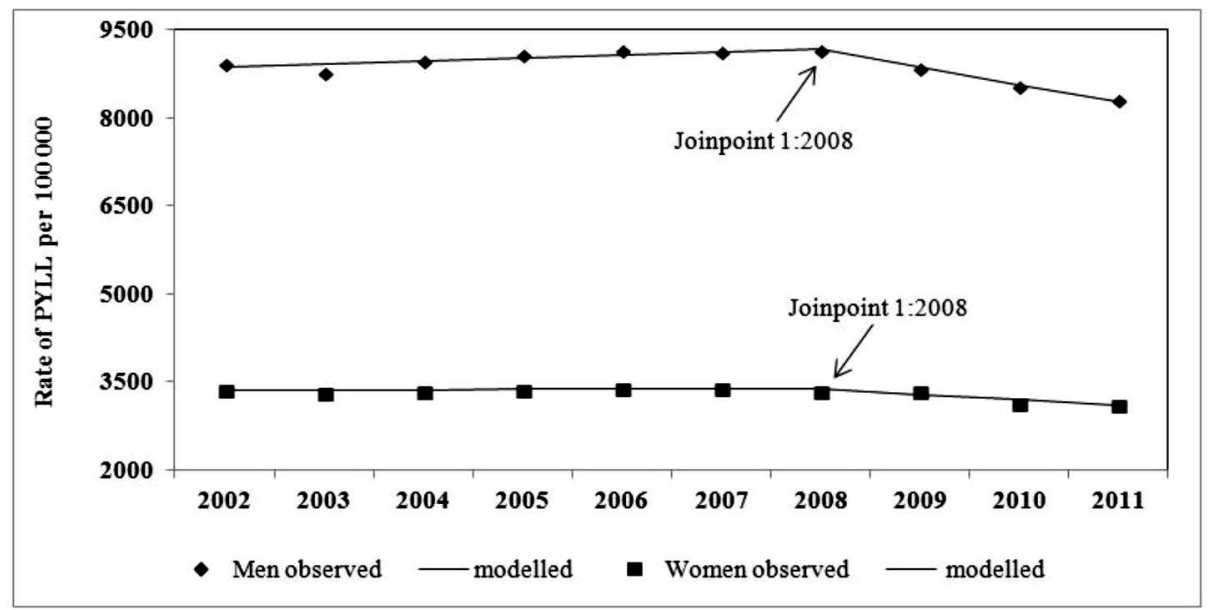

Figure 1. Rate of PYLL for all causes in Poland, years 2002-2011: observed and modeled values

Figures 2 and 3 present the proportion of PYLL due to main causes of death in the years 2002 and 2011, separately for men and women. In 2011, the main causes of premature mortality among men were external causes, responsible for $27.6 \%$ of PYLL, followed by cardiovascular diseases $-24.2 \%$ and cancer $-20.3 \%$. These three cause of death groups were responsible for $72.1 \%$ of PYLL among men. For women, the leading cause of premature mortality was cancer $-41.1 \%$ of PYLL, then cardiovascular diseases $-19.7 \%$ and external causes $-12.5 \%$. Similarly to men, these three cause of death groups were responsible for $73.3 \%$ of PYLL.

As presented in Table 2, in the years 2002-2008, the PYLL rate for men significantly decreased due to lung cancer $(\mathrm{APC}=0.8 \%, p<0.05)$ and ischaemic heart disease (APC $=2.6 \%, p<0.05$ ). After 2008, a significant de- 


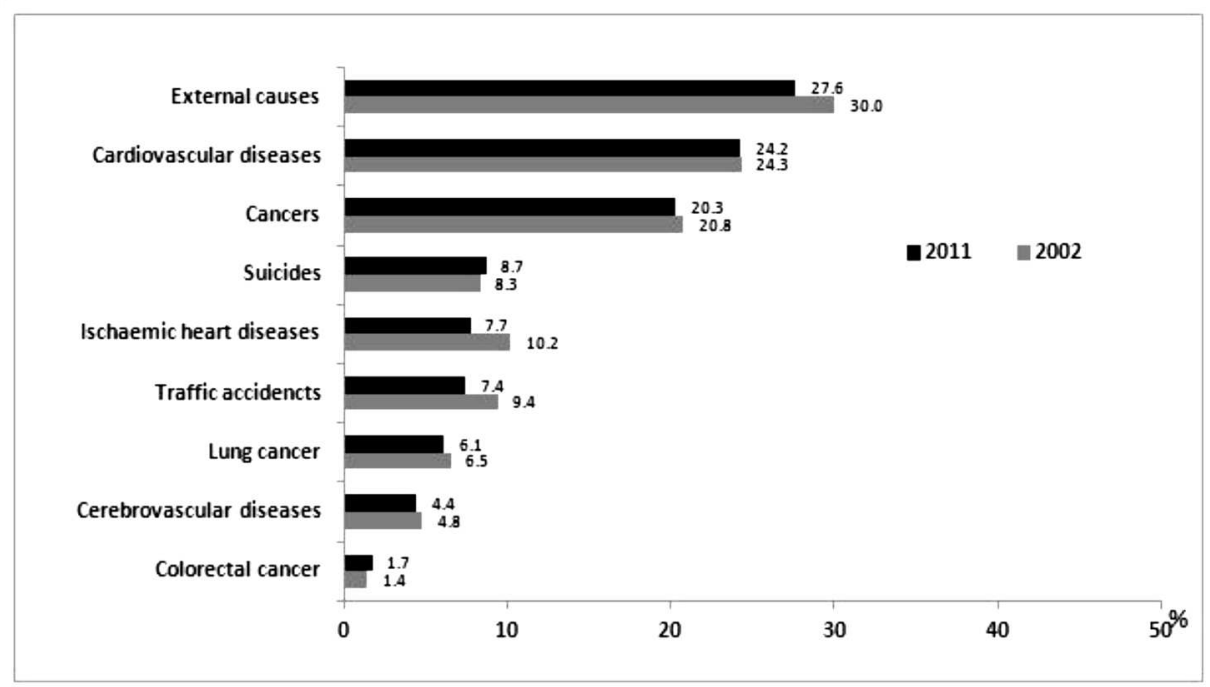

Figure 2. Potential Years of Life Lost by main causes of death among men in Poland

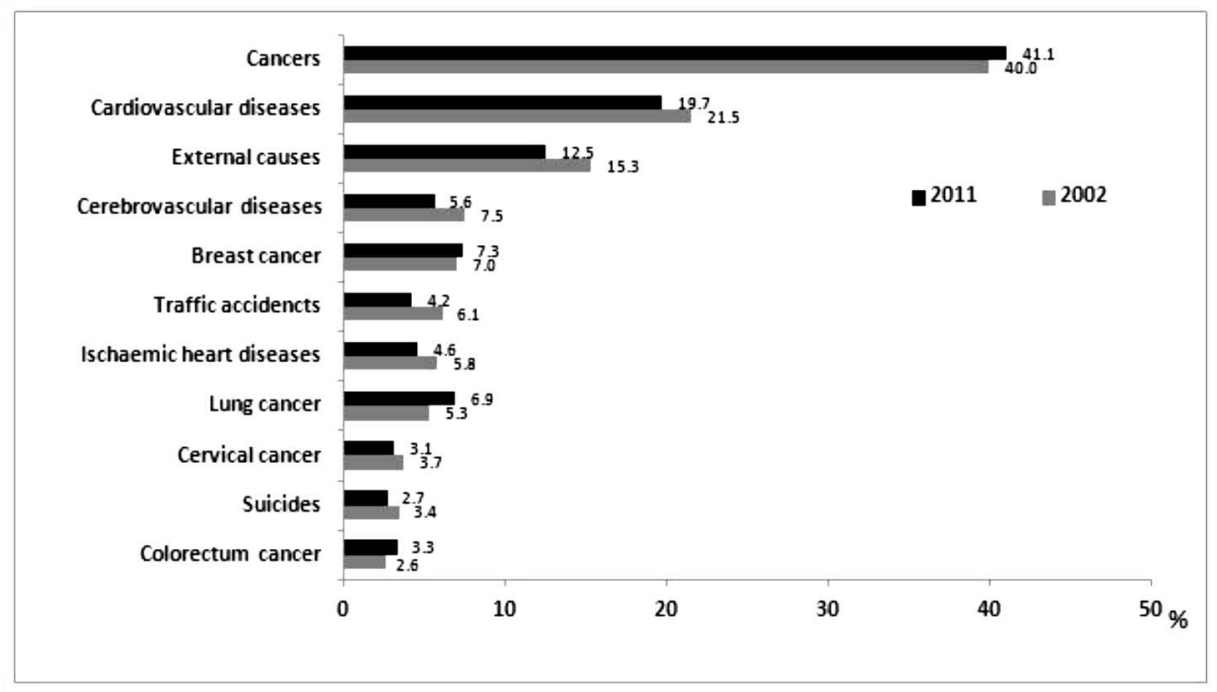

Figure 3. Potential Years of Life Lost by main causes of death among women in Poland

crease in the rate of PYLL was noted for all cancers $(\mathrm{APC}=2.1 \%, p<0.05)$, lung cancer $(\mathrm{APC}=3.2 \%, p<0.05)$, cardiovascular diseases $(\mathrm{APC}=4.7 \%$, $p<0.05)$, ischaemic heart disease $(\mathrm{APC}=6.1 \%, p<0.05)$ and cerebrovascular disease $(\mathrm{APC}=5.0 \%, p<0.05)$. During the analysed period, 
the PYLL rate decreased among men for external causes $(\mathrm{APC}=1.6 \%$, $p<0.05)$. The PYLL rate also decreased for traffic accidents $(\mathrm{APC}=4.3 \%$, $p<0.05)$.

Among women in the years 2002-2008, the PYLL rate significantly decreased only due to cardiovascular disease (APC $=0.9 \%, p<0.05)$. After 2008, a significant decrease in the PYLL rate was noted for all cancers $(\mathrm{APC}=1.3 \%, p<0.05)$. During the analysed period, the PYLL rate among women decreased for breast cancer $(\mathrm{APC}=0.7 \%, p<0.05)$, cervical cancer $(\mathrm{APC}=2.7 \%, p<0.05)$, ischaemic heart diseases $(\mathrm{APC}=3.7 \%$, $p<0.05)$, cerebrovascular disease (APC $=3.9 \%, p<0.05)$, external causes $(\mathrm{APC}=3.1 \%, p<0.05)$, traffic accidents $(\mathrm{APC}=4.9 \%, p<0.05)$, and suicides $(\mathrm{APC}=2.7 \%, p<0.05)$. In the years 2002-2011, an increase in the PYLL rate among women was noted for lung cancer $(\mathrm{APC}=2.7 \%$, $p<0.05)$.

\section{Discussion}

In Poland, from the mid 1960s to the end of the 1980s, premature mortality among men increased systematically, whereas it remained on the same level among women. After 1991, a slowdown in the trend in both men and women was seen, and then a reverse change and a decrease in premature mortality were observed (Zatoński, 1996). Despite these changes in Poland from 1995-2007, the levels of premature mortality were some of the highest in the European Union (European Commission, 2010). The results of the research show that since 2008, PYLL rate has decreased slightly among men and women for all causes of death, but the tempo of these changes was among the slowest in the EU.

In years 2002-2011 in Poland, the average PYLL rate for all causes of death was three times higher for men than for women. The biggest surplus of PYLL rate between men and women was for suicides, the smallest one - cancers. Higher premature mortality rates for men than for women are common in all parts of the world (Colin et al., 2004). In all EU countries, men die earlier than women, and in 2010, an average surplus in mortality among men in comparison to women amounted to approximately $65 \%$; in Poland it was higher and amounted to $91 \%$. Higher mortality among men in Poland occurred in all age groups, but was the highest in persons above the age of 60 (Wojtyniak et al., 2012).

The results of the research indicate that in Poland, the structure of causes of premature mortality for men and for women was different in comparison to that in the European Union. According to the OECD data in 


\section{Michalina Krzyżak et al.}

Europe (OECD, 2007), in 2007, the prime categories of causes for potential years of life lost before the age of 70 among men were external causes (29\%), cancers $(21 \%)$ and cardiovascular diseases (18\%). As for women, they were cancers $(31 \%)$, external causes $(17 \%)$ and cardiovascular diseases $(13 \%)$. In Poland in the years 2002-2011, the main causes of PYLL for men were external causes and for women cancers. Cardiovascular diseases were the second cause of premature death for both sexes.

External causes of death are potentially preventable. Traffic accidents and suicides were the leading causes of PYLL within external causes. During the study period, the PYLL rate of traffic accidents decreased in a similar way for men and women. Unfortunately, the PYLL rate for suicides among men did not change significantly and in 2011, premature mortality for this reason was higher than for traffic accidents and amounted to $8.2 \%$ of PYLL. Trends in suicides are thought to reflect changing patterns of mental health within populations, so the presented situation regarding premature mortality due to suicide among men calls for the improvement of mental health strategies to include suicide reduction targets.

Premature mortality due to cardiovascular diseases in Poland has declined since 1991 (Zatoński, 1996), but the presented study shows that the rate of PYLL for cardiovascular diseases among men has decreased since 2008. During the years of the studythe rate of PYLL decreased for ischemic heart diseases and cerebrovascular diseases among men and women. Premature mortality from cardiovascular diseases is preventable through healthier lifestyle and timely access to medical treatment.

The results of the research show that the PYLL rate due to all cancers has decreased slightly for men and women since 2008. However, unfavourable changes were prevalent for colorectal cancer in both sexes and lung cancer in women. There was a favourable and statistically significant change for lung cancer in men and for breast and cervical cancer in women.

In Poland, lung cancer is still the leading cause of death; however, the trends are different for each sex. Among men, the general mortality trend decreases slowly, whereas among women it increases rapidly. Similar changes, especially in the female population, have also been noticed in many EU countries (Tyczyński et al., 2004). In other countries, for example: France, Spain, and Italy, the trend is either stable or is decreasing (Bosetti et al., 2012).

Lung cancer is a preventable disease. The results of the research and the ones published for the country show that measures undertaken to fight tobacco smoking have a certain favourable influence among men; however, they are of a small effectiveness among women. 
In the last thirty years in Poland, rates of incidence and mortality due to colorectal cancer have increased. Among men, that increase was the fastest as far as cancers are concerned (Didkowska et al., 2011). As the results of our study have shown, the trend in premature mortality was similar. It also increased among women due to colorectal cancer. Even though the trend was not statistically significant among women, it indicates the increase of the threat of this type of cancer in Poland. The risk of death due to colorectal cancer in Poland, the Czech Republic, Slovakia and Hungary belongs to the highest in Europe, and the divergence between Poland and North-Western European countries is systematically growing (Bosetti et al., 2011).

Premature deaths due to colorectal cancer are preventable through intensified primary prevention based on the modification of risk factors related to lifestyle, secondary prevention based on colonoscopy and faecal occult blood tests, and finally, the improvement of standards of diagnosis and treatment. Population screenings carried out in the 90s showed that standards of diagnosis and treatment were rarely followed (Gatta et al., 2010).

Cervical cancer is also a cancer that can be effectively prevented. Poland is a country of mid/high risk of incidence and mortality due to cervical cancer. In Europe, the risk is higher in Romania and Bulgaria. Although general mortality due to cervical cancer is decreasing in Poland, the divergence between Poland and Western European countries is not growing smaller (Arbyn et al., 2009).

The presented results show that the premature mortality trend due to cervical cancer in Poland was similar to the general mortality trend during the years of the study, and was also too slow, which calls for the intensification of prevention efforts and for the improvement of treatment standards.

In the majority of highly developed countries, deaths due to cardiovascular diseases, cancers and external reasons constitute over $70 \%$ of potential years of life lost before the age of 70 for both men and women (Savidan et al., 2010). In most cases, these deaths are preventable thanks to measures undertaken in the field of health promotion, social education, early detection of diseases, and effective treatment and rehabilitation (Gromulska et al., 2008). Therefore, knowledge about the causes of and trends in premature death in a population is essential to determining priorities in health care planning and to measuring their effectiveness. Such measures, especially the ones concerning preventive medicine at primary and secondary levels and improvement in availability of optimal treatment, as well as better socio-economic conditions of a population, may contribute to the decrease of potential years of life lost. 
Michalina Krzyżak et al.

\section{Conclusions}

Among men after 2008, for all analysed causes of death except for colorectal cancer, favourable changes were noted. Among women, the PYLL rate systematically increased for colorectal cancer and lung cancer. After 2008, favourable changes were noted for all-cause deaths and cancers.

The presented epidemiological situation for premature mortality in Poland shows that in the majority of cases it is caused by preventable deaths, which suggests a need to intensify measures in primary and secondary prevention.

\section{R E F E R E N C E S}

Arbyn, M., Raifu, A. O., Weiderpass, E., Bray, F., \& Anttila, A. (2009). Trends of cervical cancer mortality in the member states. Eur $J$ Cancer, 45(15), 2640-2648.

Bosetti, C., Levi, F., Rosato, V., Bertuccio, P., Lucchini, F., Negri, E., \& La Vecchia, C. (2011). Recent trends in colorectal cancer mortality in Europe. Int J Cancer, 129(1), 180-191.

Bosetti, C., Malvezzi, M., Rosso, T., Bertuccio, P., Gallus, S., Chatenoud, L., Levi, F., Negri, E., \& La Vecchia, C. (2012). Lung cancer mortality in European women: trends and predictions. Lung Cancer, 78, 171-178.

Colin, M., Thies, B., \& Doris, M. F. (2004). Global burden of Disease: update 2004. World Health Organisation.

Didkowska, J., Wojciechowska, U., \& Zatoński, W. (2011). Nowotwory złośliwe w Polsce w 2009 roku. Warszawa: Centrum Onkologii, Instytut im. M. Skłodowskiej-Curie.

European Commission. (2010). Health trends in the UE.

Gardner, J., \& Sanborn, J. (1990). Years of potential life lost (YPLL) - what does it measure? Epidemiology, 1(4), 322-329.

Gatta, G., Zigon, G., Aareleid, T., Ardanaz, E., Bielska-Lasota, M., Galceran, J., Góźdź, S., Hakulinen, T., Martinez-Garcia, C., Plesko, I., Zakelj, M. P., Rachtan, J., Tagliabue, G., Vercelli, M., \& Faivre, J. (2010). Patterns of care for European colorectal cancer patients diagnosed 1996-1998: a EUROCARE High Resolution Study. Acta Oncol., 49(6), 776-783.

Gromulska, L., Wysocki, M. J., \& Goryński, P. (2008). Lata przeżyte w zdrowiu (Healthy Life Years, HYL) - zalecany przez Unię Europejską syntetyczny wskaźnik sytuacji zdrowotnej ludności. Przegl Epidemiol, 62, 811-820.

Kim, H. J., Fay, M. P., Feuer, E. J., \& Midthune, D. N. (2000). Permutation tests for joinpoint regression with applications to cancer rates. Stat Med, 19(3), 335-351. (correction: 2001; 20: 655) 
Joinpoint Regression Analysis of Potential Years of Life Lost Due to Main...

National Cancer Institute, Statistical Research and Applications Branch. (2013). Joinpoint Regression Program (Version 4.0.4.).

OECD (2007). Health at a Glance 200\%: OECD Indicators. OECD Publishing. DOI: 10.1787/health_glance-2007-en.

OECD (2011). Health at a Glance 2011: OECD Indicators. OECD Publishing. DOI: 10.1787/health_glance-2011-en.

Romeder, J., \& McWhinnie, J. (1977). Potential Years of Life Lost Between Ages 1 and 70: An Indicator of Premature Mortality for Health Planning. Int $J$ Epidemiol, 6(2), 143-151.

Savidan, A., Junker, Ch., Cerny, T., \& Ess, S. (2010). Premature mortality in Switzerland from 1995-2006: causes and trends. Swiss Med Wkly., 140:w13077. DOI: 10.4414/smw.2010.13077.

Tyczyński, J. E., Bray, F., Aareleid, T., Dalmas, M., Kurtinaitis, J., Plesko, I., Pompe-Kirn, V., Stengrevics, A., \& Parkin, D. M. (2004). Lung cancer mortality patterns in selected Central, Eastern and Southern European countries. Int J Cancer, 109(4), 598-610.

Wojtyniak, B., Goryński, P., \& Moskalewicz, B. (2012). Sytuacja zdrowotna ludności Polski i jej uwarunkowania (pp. 58-59). Warszawa: Narodowy Instytut Zdrowia Publicznego.

World Health Organization. (2004). International Statistical Classification of Diseases and Health Related Problems: tenth revision (2nd ed.). Geneva: WHO.

Zatoński, W. (1996). Evaluation of health in Poland since 1988. Warszawa: Centrum Onkologii, Instytut im. M. Skłodowskiej-Curie. 